\title{
Design and experiment of anti-vibrating and anti-wrapping rotary components for subsoiler cum rotary tiller
}

\author{
Kan Zheng ${ }^{1}$, Allen D. McHugh ${ }^{2}$, Hongwen $\mathrm{Li}^{1}$, Qingjie Wang ${ }^{1}$, Caiyun $\mathrm{Lu}^{1}$, Hongnan $\mathrm{Hu}^{1}$, \\ Wenzheng Liu ${ }^{1}$, Zhiqiang Zhang ${ }^{1}$, Peng Liu ${ }^{1}$, J in $\mathrm{He}^{1 *}$ \\ (1. College of Engineering, China Agricultural University, Beijing 100083, China; \\ 2. International Maize and Wheat Improvement Centre (CIMMYT), Dhaka 1213, Bangladesh)
}

\begin{abstract}
The commonly used subsoiling cum rotary tiller machine (SRT) in Northern China is a combination of subsoiler and horizontal rotary tiller, however backfilling of the subsoiling slot, excessive vibration and plant residue wrapping on rotary components has been rarely considered. Therefore, the rotary components and assembly were redesigned to address these issues and to an SRT fitted with IT225 short curve rotary blades behind the V-shape subsoiling slots and IIT245 long curve rotary blades between the tines. Long and short blades were fitted on a rotor in a double helix, with optimal spiral angles of $65^{\circ}$ and $90^{\circ}$, and phase angle of $147^{\circ}$ and $180^{\circ}$, respectively. Compared with the commonly used SRT (CSRT), the additional anti-wrapping cutting blades in the circumferential and axial direction of ASRT could remove hanging residue on the blade holders, wrapping on the rotor and formation of an isolation layer. Moreover, the cutting edge curve of anti-wrapping cutting blades was an exponential curve. Field tests demonstrated that the redesigned SRT with anti-vibrating and anti-wrapping rotary components (ASRT) had was a significant advancement over the CSRT. Moreover, the working depth of rotary tillage was more stable, while other observations confirmed that backfilling of the subsoiling slot was also improved.
\end{abstract}

Keywords: subsoiling, rotary tiller, anti-vibration, anti-wrapping, backfill, tillage

DOI: $10.25165 /$ j.ijabe.20191204.4369

Citation: Zheng K, McHugh A D, Li H W, Wang Q J, Lu C Y, Hu H N, et al. Design and experiment of anti-vibrating and anti-wrapping rotary components for subsoiler cum rotary tiller. Int J Agric \& Biol Eng, 2019; 12(4): 47-55.

\section{Introduction}

The combination of subsoiling and rotary tillage creates a flat fine tilth on the soil surface and shatters deep plow pans at the same time. The combination of the two operations has a number of stated advantages: reduction in tractor hours; reduced soil compaction $^{[1]}$; shorter operation cycle time; reduced power consumption by $20 \%$ to $25 \%$ compared to subsoiler or rotary cultivator alone $\mathrm{e}^{[2,3]}$. Crop production advantages include: improved efficiency in plant dry matter conversion and water use; enhanced root growth; and improved crop yield ${ }^{[4-7]}$.

Subsoiler cum rotary tiller (SRT) is a simple combination of subsoil shanks and a horizontal rotary tiller ${ }^{[8,9]}$, which is commonly

\section{Received date: 2018-05-18 Accepted date: 2019-06-09}

Biographies: Kan Zheng, $\mathrm{PhD}$ candidate, research interests: conservation tillage and equipment, Email: zhengkan0219@163.com; Allen D. McHugh, $\mathrm{PhD}$, research interests: cropping systems agronomist, Email: A.McHugh@ cgiar.org; Hongwen Li, PhD, Professor, research interests: conservation agriculture, agriculture machine and equipment engineering, Email: lhwen@ cau.edu.cn; Qingjie Wang, PhD, Professor, research interests: conservation tillage and equipment, Email: wangqingjie@cau.edu.cn; Caiyun Lu, Postdoctor, Associate Professor, research interests: conservation tillage and equipment, Email: lucaiyun@cau.edu.cn; Hongnan Hu, PhD candidate, research interests: conservation agriculture machinery, Email: 357954821@qq.com; Wenzheng Liu, $\mathrm{PhD}$ candidate, research interests: conservation agriculture machinery, Email: 1149655879@qq.com; Zhiqiang Zhang, PhD candidate, research interests: conservation agriculture machinery, Email: zhangzhiqiang531@ 163.com; Peng Liu, Master candidate, research interests: conservation agriculture machinery, Email: 1023622964@qq.com.

*Corresponding author: Jin $\mathbf{H e}, \mathrm{PhD}$, Professor, research interests: conservation agriculture, agriculture machine and equipment engineering. Mailing address: College of Engineering, China Agricultural University, No.17, Qinghuadonglu, Haidian District, Beijing 100083, China. Tel: +86-1062737300, Email: hejin@cau.edu.cn. used in the North China Plain (NCP). SRT mixes and buries a large amount of plant residue, and breaks/shatters the deeper compaction layers, from the winter wheat-summer maize double cropping system of. Planting areas are quite large, and the farming cycle is short due to the harsh cold winters ${ }^{[10]}$. The SRT of subsoiler shanks were evenly mounted in front of rotary tiller. Slots were formed in the soil surface with some shattering after subsoiling, however the rotor blades are unevenly stressed when working across the disturbed surface. Compared with separate rotary tillage operations, the vibration of the rotary parts of the SRT are much larger, which reduces the longevity of component parts such as; bearings, oil seals, gears and blades. In addition, rotary blades wear unevenly, seriously reducing the efficiency and reliability of the $\mathrm{SRT}^{[11]}$. In fields, where plant residue is retained, there is an increased incidence of straw and weeds wrapping around the rotor, which reduces tillage depth and the quality of operations $^{[12]}$. However, it takes considerable time for the SRT to service the land and the rotary parts are easily clogged and wrapped by prolific weeds in the NCP. Therefore, to increase efficiency and operational performance, the SRT requires reduced vibration and a capacity to avoid weed and straw wrapping.

At present, the parameters of rotary tiller were studied. Li et al. ${ }^{[13]}$ studied rotary blade by designing with smoothed particle hydrodynamics modelling and Taguchi method, which reduced power consumption compared to conventional rotary blade by $12.4 \%$; Matin et $\mathrm{al}^{[14-16]}$. studied the effect of three blade geometries (conventional, half-width and straight) at four rotary speeds $(125,250,375$, and $500 \mathrm{r} / \mathrm{min})$ on torque, power and energy characteristics. The results showed that the soil fraction was not significant under the straight blade, and the amount of soil disturbance and torque was significantly better than that of the other two kinds of rotary knife; Saimbhi et $\mathrm{al}^{[17]}$. Studied the 
power consumption difference among rotary blades of $\mathrm{C}$ style, $\mathrm{L}$ style and C-L style, and results showed that $\mathrm{C}$ style had less power consumption. There are some studies on combination arrangement of rotary blades. Yang et $\mathrm{al}^{[18]}$. studied three types of blade (bent C, straight and hoe) in four tool configurations at four rotary speeds $(180,280,380$ and $510 \mathrm{r} / \mathrm{min})$ in paddy soil. Results showed that the mixed blade configuration (central hoe blades with two straight blades aside) was optimal; Lee et $\mathrm{al}^{[19]}$. reported that rotor shaft with four rotary blades had the lowest torque variation and torque requirement, and the soil breaking ratio was $24.4 \%$. Studies on vibration reduction and anti-winding in rotary tillers were carried out. Chaturvedi et $\mathrm{al}^{[20]}$. studied the influence of synthetic rubber, polyurethane and combination of rubber and polyurethane on the vibrations of rotary power tiller. It was reported that the maximum vibration reductions were achieved with the rubber in all three operational conditions; $\mathrm{Xu}$ et $\mathrm{al}^{[21]}$. found that the rotary tiller winded up the straw and the weed were mainly related to the length of the straw and the weed, the radius of the rotary blade shaft, and the friction coefficient of the cutter shaft. And increase the radius of the knife shaft could reduce the rotary tiller winding straw and weeds. These studies were mainly focused on shapes and parameters of rotary blades, relationships between power consumption and tilling parameters, vibration reduction, and anti-wrapping in single rotary tillers. However, there is little research on anti-vibration and anti-wrapping on SRT roto-tiller components.

In the view of these issues and according to the required soil effects after subsoiling, the rotary blades, their arrangement, and the addition of anti-wrapping blades were redesigned to reduce vibration and wrapping. To be specific this study aimed to: (1) to design rotary blades and their arrangement, and find out vibration effects on blade shaft, (2) to analyze wrapping process and combine the straw distribution situation to design anti-wrapping blade and decrease wrapping, (3) to verify the operation performance of ASRT. Therefore this study hopes to provide suggestions to improve SRT performance in China.

\section{Design principles and structures}

\subsection{Vibration reduction and anti-wrapping of rotary components}

Key components of the SRT with anti-vibrating and anti-wrapping rotary components (ASRT) are shown in Figure 1. Under normal operations, the SRT shank and points operate in the non-tilled area ahead of the roto-tiller, which forms a V-shaped area of loosened soil (Figure 1b), with the roto-tiller rotates in the direction of travel i.e. counter clockwise (Figure 1a). The soil in the V-shape zone is crushed, cut, shredded and thrown by short blades, helically mounted on the rotor shaft. Simultaneously, uplifted soil and subsoiling slots are flattened and filled by the short blades to retain soil moisture. Long blades mounted on an alternate helix are used to break, mixed and smooth the soil between the subsoiling shanks. Consequently, the forces on rotary components mounted on a single helix vary depending on their position in relation to the subsoiler disturbance zone. Blades of different lengths, arranged on two helical lines on the rotor, can reduce forces induced within the same spiral, reduce the impact and vibration along the blade axis and improve blade life, gears, bearings and other parts. Weeds and straw disturbed by the subsoil shank, often become wound on the blades and rotor. The rotor is fitted with anti-winding blades and a counterweight baffle for each set of blades. Plant material caught on the blade seat and/or wrapped on the rotor, slide and then are cut by the anti-wrapping blades. This reduces winding and occlusion by weeds and straw on the rotor and blades and ensures the reliability of machine operations.

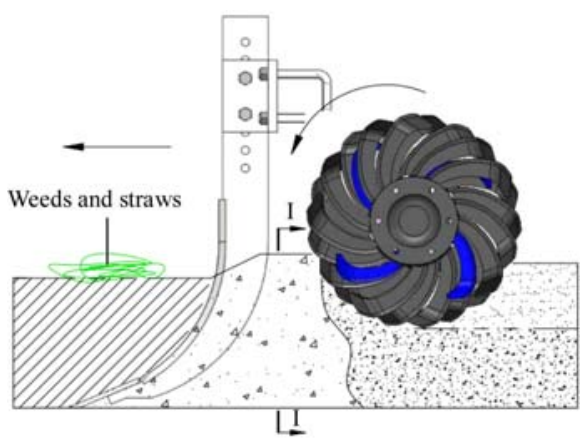

a. Process of the subsoiling and rotary tillage combined operation

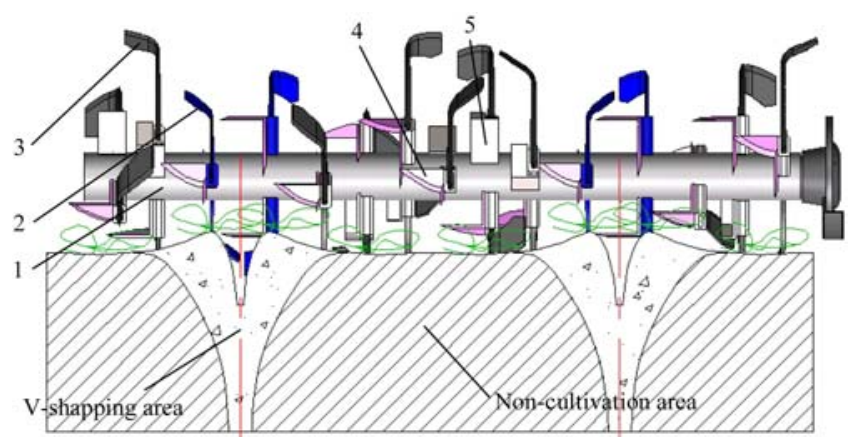

b. I-I Soil horizontal profile after subsoiling

1. Blade shaft 2. Short blade 3. Long blade 4. Anti-wrapping blade

5. Counterweight baffle

Figure 1 Design of vibration reduction and anti-wrapping components

\subsection{Machine structure and main structural parameters}

As well as vibration reduction and anti-wrapping components, the ASRT includes a breast board, body frame, gearbox, hanger and blade rotor (Figure 2). The 4 subsoiling shanks with chisel points
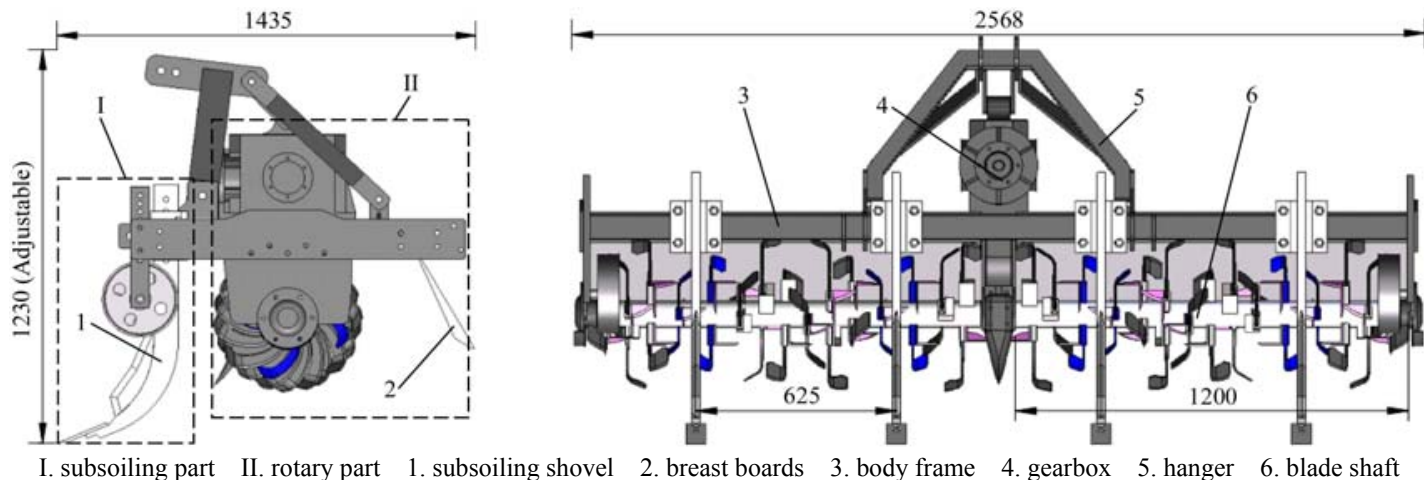

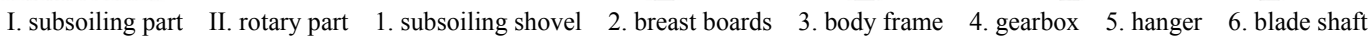

Figure 2 Structural diagram of subsoiling and rotary tillage combined machine 
are mounted $625 \mathrm{~mm}$ apart on the front bar of the machine. The subsoiling shanks and points were designed according to the soil properties of tillage layer, plow pan and subsoil layer commonly found on the NCP. The shanks are designed to reduce resistance and power requirement and can reduce plant material from wrapping on shanks ${ }^{[22]}$. The SRT operating width is $2500 \mathrm{~mm}$ and has a power requirement of $\geq 66.2 \mathrm{~kW}$. The dimensions of machine are $1435 \mathrm{~mm}$ in length, $2568 \mathrm{~mm}$ in width and $1230 \mathrm{~mm}$ in height. Rototiller operating depth is $\leq 200 \mathrm{~mm}$, with a tillage width of $1200 \mathrm{~mm}$ at $250-350 \mathrm{r} / \mathrm{min}$. The operating speed is $1.8-3.96 \mathrm{~km} / \mathrm{h}$.

\section{Key redesign parameters and verification of ASRT}

Due to changed soil conditions following subsoiling, vibration reduction and anti-wrapping capabilities of the rotary tiller were re-designed. The focus was on rotary tiller blades to reduce the vibration and considered the design and arrangement of the blades. Based on the outcome, the structure and location of the anti-wrapping blades and counterweight baffles were modified.

\subsection{Vibration reduction design of rotary tiller blade rotor}

\subsubsection{Rotary tiller blade design}

As described previously, V-shape areas were formed where the soil condition was between phases, and raised a certain height $\left(H_{1}\right)$ by the action of subsoiler. In order not to affect the soil surface flatness after the operation, the volume of the soil thrown by the roto-tiller blades in subsoiling area and the non-tilled area should be the same. In addition, blades should impart specific soil flow characteristics to achieve adequate backfill of the subsoiling slots. Accordingly, rotary tillage depth in the subsoiling areas and non-tilled areas with the ASRT should be consistent. That is, long blades should throw the same soil volume as that of short blades according to the working depth of long blades (no tilled zones) and short blades (subsoiled zones). The positional relationship of rotary tillage blades and soil is shown in Figure 3a. The short blades operate at depth $\mathrm{H}_{3}$, which is equivalent to the long blade operating at depth $H_{4}$. The difference in rotational radius of long blades and short blades can be obtained by determining the actual height $\left(H_{1}\right)$ of the soil, which was lifted by the subsoiling action and thus the compressed height of the upper soil moved by the subsoiler points was $h^{[23]}$, which can be determined from the geometric relationships in Figure 3b:

$$
\left\{\begin{array}{l}
H_{1}=H_{2}-h \\
H_{2}=L \sin \alpha \\
h=S_{1}\left(\frac{1}{2} \sin (2 \alpha)-\sin ^{2} \alpha \tan \varphi\right) \\
S_{1}=L \cos \alpha
\end{array}\right.
$$

where, $H_{1}$ is the actual height of soil lifted by the subsoiler point; $\mathrm{H}_{2}$ is the theoretical height of soil lifted; $h$ is the actual height of soil compressed by subsoiler point; $\alpha$ is the penetration angle of the subsoiler point; $S_{1}$ is the length of subsoiler point in the horizontal plane; $L$ is the length of the subsoiler point; $\varphi$ is the friction angle between subsoiler point and soil.

According to the national standards JB/T9788-1999 "Subsoiler and share shaft" "[24], the penetration angle of the subsoiler point $\alpha$ was $23^{\circ}$, the length $(L)$ was $165 \mathrm{~mm}$, the width $B$ was $60 \mathrm{~mm}^{[25]}$. The average friction angle between subsoiler point and soil $\varphi$ was measured as $23.12^{\circ}$ by a MXD-01 Friction Coefficient Measuring Instrument. Substituting these values into Equation (1), the height of soil lifted by the subsoiler point $\left(H_{1}\right)$ was calculated as $19.17 \mathrm{~mm}$, and therefore we assigned a value of $20 \mathrm{~mm}$ to $H_{1}$.
Referring to $G B / T 5669-2008$ "Rotary Tiller-Rotary Blades and Blade Holders" ${ }^{, 26]}$, the long rotary tillage blades (Type IIT245) ${ }^{[27]}$ designed for heavy residue and hard soils, its rotating radius $R_{1}$ is $245 \mathrm{~mm}$ and its operation width $b_{1}$ is $50 \mathrm{~mm}$. The short tillage blade (Type IT225) ${ }^{[27]}$ designed for loose and soft soil, has a rotating radius $R_{2}$ is $225 \mathrm{~mm}$. In order to increase soil throw, the width of short rotary tillage blade was $60 \mathrm{~mm}$. Both blade types are forged from $65 \mathrm{Mn}$ steel and the long rotary blade soil contact section was quenched after forging.

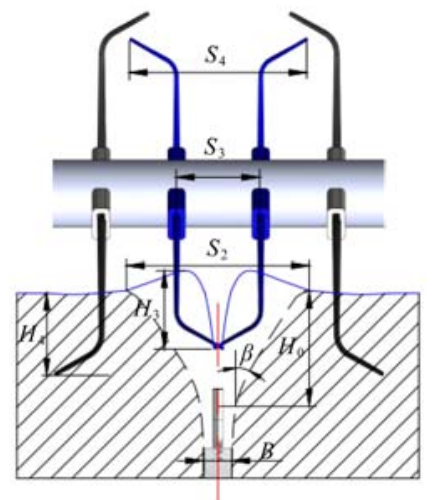

a. Positional relation of rotary tillage blades and soil

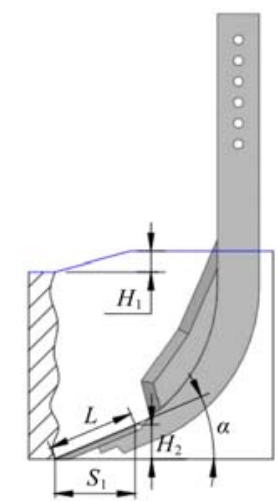

b. Positional relation of subsoiler and soil
Figure 3 Positional relation of subsoiler, rotary blades and soil

On ASRT machines employed in rainfed farming, the number of rotary blades in a blade set is 2 to 3 , and the rotary speed ratio set at greater than $4^{[28,29]}$. Refer to commonly used subsoiling cum rotary tiller (CSRT) machines, the number of rotary blades (long and short rotary blade) in the blade set was 2. By calculating the width of V-shape subsoiling area the number of short blades and the distance of blade holders can be determined. The width of $\mathrm{V}$ shaped subsoiling area is $S_{2}=B+2 H_{0} \tan \beta$, where $H_{0}$ is the critical depth of subsoiling ${ }^{[30]}$ with a value of $200 \mathrm{~mm} ; \beta$ is the sector angle ${ }^{[31]}$ of $22.5^{\circ}$; the width of subsoiler point is $60 \mathrm{~mm}$, providing a V shaped subsoiling area of $225.69 \mathrm{~mm}$. Therefore, to ensure the short blades cover the $\mathrm{V}$ shaped subsoiling area, the tilling width $S_{4}(220 \mathrm{~mm})$ should be matched to width of the V-shape subsoiling area $\left(S_{2}\right)$ as much as possible. Considering the working width of the short rotary tillage blades, two blade sets ( 4 in all) (Figure 3) were installed behind the subsoiler, with a distance $110 \mathrm{~mm}$ between the two blade sets $\left(S_{3}\right)$.

3.1.2 The arrangement of rotary tillage blades on the blade roller

The appropriate arrangement of rotary tiller blades on the rotor can improve the tillage quality, power consumption, rotary parts balance, blade wear uniformity, and reduce vibration and shock on the machine, prolonging the service life of the transmission and other components ${ }^{[32]}$. In this paper, the ASRT was a mid-mounted transmission system, with two left and right rotors. The rotary tiller blades were symmetrical arranged in double-headed spiral, to offset the forces on the rotor, reduce bearing load and horizontal vibration of the machine. To ensure complete tillage, the blades are alternately mounted, facing inward and outward in each 4 blade cutter head. The width of the rotary tiller $(D)$ was $1200 \mathrm{~mm}$. The total tillage width of the short rotary tillage blades was $4 S_{4}=880 \mathrm{~mm}$ (Figure 3a). The total number of long rotary tillage blades $\left(Z^{\prime}\right)$ installed on rotor can be obtained from $Z^{\prime}=\left(2 D-4 S_{4}\right) z / b^{[24]}$, where $z$ is the number of blades on the same cutter-head in this case $z=2 ; b^{\prime}$ is the distance from the adjacent rotary tiller blades, to the end of the rotary tillage blades working in the soil. In this case the distance between the adjacent 
rotary tillage blades $b^{\prime}$ is greater than the working width of the rotary tillage blades $b(b=50 \mathrm{~mm})$, namely $b^{\prime}=b+\Delta b$, where $\Delta b$ often takes the value of 15 to $20 \mathrm{~mm}$, in this design the value of $\Delta b$ is $20 \mathrm{~mm}$. The number of the long rotary blades $Z^{\prime}$ installed and considering the overlap between the long and short rotary blades, the number of the long rotary blades was 44 . The number of long blades $\left(Z_{1}\right)$ on each left and right rotors was 22 , while the number of short blades $\left(Z_{2}\right)$ on each rotor was 8 (Figure 5).

Considering the difference in soil condition (Figure 4) and blade length, the two sets of blades were arranged in a double helix to reduce vibrations and variable force induction. The long blades, working in the uncultivated area, were arranged in a spiral, with an optimal helix angle $\theta_{1}{ }^{[33]}$ derived from $4 \times\left(360^{\circ} / Z_{1}\right)$ was $65.45^{\circ}$, rounded to $65^{\circ}$. The short blade optimal helix angle $\theta_{2}$ was derived from is $2 \times\left(360^{\circ} / Z_{2}\right)$ and was $90^{\circ}$. In order to prevent clogging and wrapping during operations, the phase angle of the adjacent two blade holders, on the same cutter head, should be greater than $110^{\circ}$. Considering the interference of the long rotary tillage blade with the short rotary tillage blades, the long rotary tillage blade phase angle and the short rotary tillage blade phase angle was set to $147^{\circ}$ and $180^{\circ}$ respectively. Figure 5 shows the arrangement of these blades on the rotor.

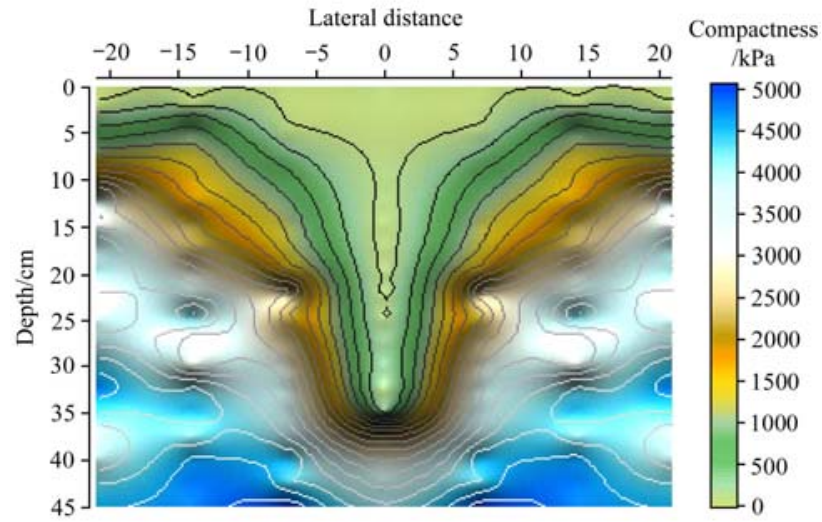

Figure 4 Distribution of soil compactness after subsoiling

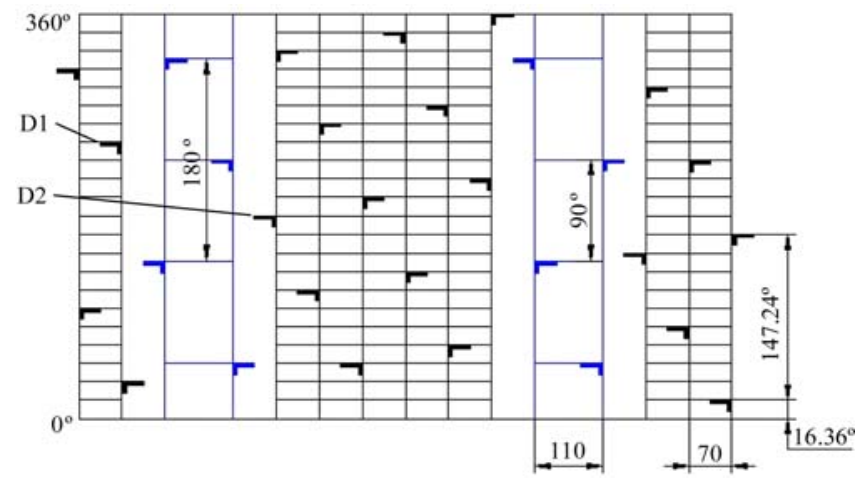

Figure 5 Arrangement of the rotary blades on the shaft of ASRT

\subsection{Anti-wrapping design of rotary tiller rotor on SRT}

3.2.1 Analysis of factors affecting the wrapping of rotary shaft

The process of straw and weeds wrapping around the blade seat and shaft was analyze. It was also assumed that straw and weeds wrapped evenly around on the shaft with the same thickness and tensile strength; the adhesion to the soil particles was not considered; and the centrifugal force generated by the rotation of the shaft was ignored. The shaft moved horizontally at a speed of $v_{\mathrm{m}}$, and rotated clockwise with rotational speed $n$ and Figure 6 showed the force analysis diagram when the shaft was wrapped. A coordinate system with the central axis of the tool axis as the origin, the horizontal direction as the x-axis, and the vertical direction as the $\mathrm{y}$-axis was established. Then, a micro-arc $\mathrm{d} L$ was intercepted from the wrapped straw or weeds, and the corresponding angle was $\mathrm{d} \alpha_{0}$. So the friction between the shaft and the straw and weed $f \mathrm{~d} F_{\mathrm{N}}$ could be obtained as shown in Equation (2).

$$
\left\{\begin{array}{l}
\mathrm{d} F_{N}=F_{0} \sin \frac{\mathrm{d} \alpha_{0}}{2}+\left(F_{0}+\mathrm{d} F_{0}\right) \sin \frac{\mathrm{d} \alpha_{0}}{2} \\
f \mathrm{~d} F_{N}=\left(F_{0}+\mathrm{d} F_{0}\right) \cos \frac{\mathrm{d} \alpha_{0}}{2}-F_{0} \cos \frac{\mathrm{d} \alpha_{0}}{2}
\end{array}\right.
$$

where, $f$ is the coefficient of friction between shaft the straw and weeds; $F_{0}$ and $F_{0}+\mathrm{d} F_{0}$ are the tension at both ends of the micro-arc, $\mathrm{d} F_{\mathrm{N}}$ is the pressure of the shaft to the micro-arc.

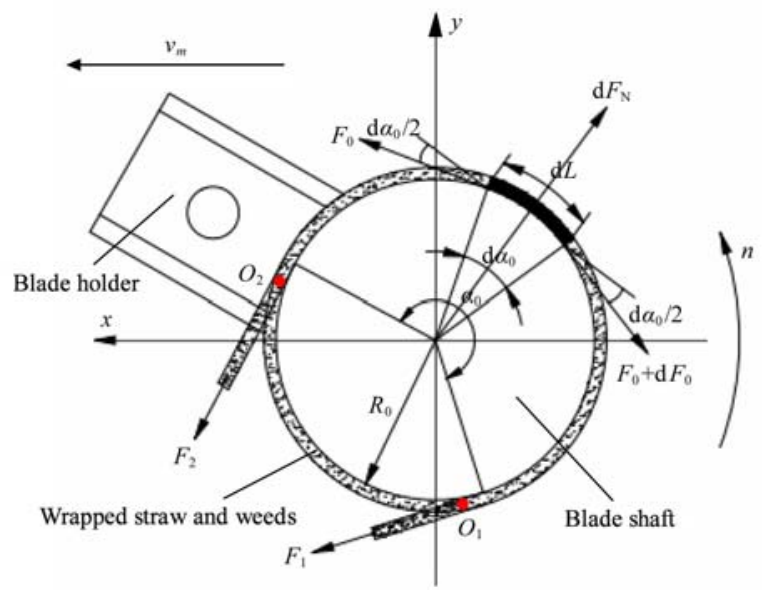

Figure 6 Force analysis diagram when the shaft was wrapped

According to the infinitesimal method, $\sin \left(\mathrm{d} \alpha_{0} / 2\right)=\mathrm{d} \alpha_{0} / 2$; $\cos \left(\mathrm{d} \alpha_{0} / 2\right)=1$. Straw and weeds are small deformed materials, ignoring the second order trace $\mathrm{d} F_{0}\left(\mathrm{~d} \alpha_{0} / 2\right)$, then Equation (3) could be obtained from Equation (2)

$$
\frac{\mathrm{d} F_{0}}{F_{0}}=f \mathrm{~d} \alpha_{0} \rightarrow \int_{F_{2}}^{F_{1}} \frac{\mathrm{d} F_{0}}{F_{0}}=\int_{0}^{\alpha_{0}} f \mathrm{~d} \alpha_{0} \rightarrow F_{1}=F_{2} \mathrm{e}^{f \alpha_{0}}
$$

where, $F_{1}$ is the critical strain force of straw and weeds at $O_{1}(\mathrm{~N})$; $F_{2}$ is the critical strain force of straw and weeds at $O_{2}(\mathrm{~N})$. Then the maximum wrapping force $F_{\mathrm{e}}=F_{1}-F_{2}$. When the straw and weeds are hung on, there is a sudden change of the structure formed by the blade holder and the shaft, and the tension force at both ends is $F^{\prime}$, then $F_{1}+F_{2}=2 F$. Combined with Equation (3), the maximum wrapping force $F_{\mathrm{e}}$ is obtained by Equation (4)

$$
F_{e}=2 F^{\prime}\left(1-\frac{2}{\mathrm{e}^{f \alpha_{0}}+1}\right)
$$

where, e is the base of natural logarithm, and approximately equal to $2.718 ; \alpha_{0}$ is the wrapping angle, and the value is $L / R$, where $L$ is the length of the wrapped straw or weeds, and $R_{0}$ is the shaft diameter.

Therefore, maximum wrapping force $F_{\mathrm{e}}$ related to the tensioning force $F$, friction coefficient $f$ between the shaft and straw and weeds, length of the straw and weeds $L, R_{0}$ is the shaft diameter. $\quad F_{\mathrm{e}}$ is proportional to $F$; When $F, L$ and $f$ remain fixed, $F_{\mathrm{e}}$ decreases with the increase of $R_{0}$. When $F, f, R_{0}$ remain fixed, $F_{\mathrm{e}}$ decreases with the decrease of $L$; When $F, R_{0}$ and $L$ remain fixed, $F_{\mathrm{e}}$ decreases with the decrease of $f$. The length of straw and weeds and the friction coefficient between shaft and straw is hard to change, therefore, in order to reduce wrapping, structure can be improved as follows: (1) improving the sudden change between the structure of the blade holder and shaft, so as to reduce the straw and weeds hanging and reduce the tension force $F$; (2) increasing rotary radius of the shaft which can effectively reduce the shaft 
wrapping.

\subsubsection{Design of anti-wrapping cutter blades}

Two anti-wrapping cutter blades were installed on the blade seat, which was designed to cut hanging weeds in the circumferential direction and in the axial direction to cut wrapped straw and weeds. An exponential cutting edge curve was chosen for effective cutting in both directions, as shown in Figure 7 and designed from the following; Take any point $\mathrm{B}$ in the cutting edge curve and set the pole radius $\mathrm{OB}$ of $\mathrm{B}$ point as $\rho$, polar angle as $\theta$, while $\rho=\rho(\theta)$. When pole radius $\rho$ and the polar angle $\theta$ increased $\Delta \rho, \Delta \theta$, the polar coordinates of $\mathrm{C}$ point were obtained $(\rho+\Delta \rho$, $\theta+\Delta \theta$ ), and the static slip angle of $\mathrm{C}$ point was $\varphi$, which was the angle between the direction of $\mathrm{C}$ point velocity and velocity tangent and the value was ${ }^{[24]} \varphi_{0}-K \theta$, where $\varphi_{0}$ is the static slip angle of the starting point of the cutting edge curve; and $K$ is the static slip angle reduction ratio on the cutting edge curve. When $\Delta \theta$ and $\Delta \rho$ were infinitely close to zero, the length of arc $\mathrm{CB}$ was approximately equal to length straight line CB. According to the geometric relation in Figure $7 \mathrm{a}, \varphi=\sigma$. The static slip angle relation of point $\mathrm{C}$ was:

$$
\left\{\begin{array}{l}
\tan \varphi=\frac{\overline{D B}}{\overline{C D}}=\lim _{\Delta \theta \rightarrow 0, \Delta \rho \rightarrow 0} \frac{\rho \sin \Delta \theta}{\rho+\Delta \rho-\rho \cos \Delta \rho} \\
\varphi=\varphi_{0}-K \theta
\end{array}\right.
$$

Simplified the limit of Equation (5), and integrated

$$
\int \frac{1}{\rho} \mathrm{d} \rho=\int \cot \left(\varphi_{0}+K \theta\right) \mathrm{d} \theta \rightarrow c \rho=\left[\sin \left(\varphi_{0}+K \theta\right)\right]^{\frac{1}{K}}
$$

where, $c$ was constant.

When the polar angle $\theta$ was $0, c$ was calculated as $\left[\left(\sin \varphi_{0}\right)^{1 / K}\right] / \rho_{0}$ from Equation (6), where $\rho_{0}$ was the pole radius starting from start point of the edge curve. Established a rectangular coordinate system with polar axis as the rectangular axis, $\pi / 2$ polar angle as radial the positive axis of the $y$-axis and the pole is the right-angled coordinate system of the coordinate origin (Figure 7a). The polar coordinate system was connected with the rectangular coordinate Equation (6) and combined with the constant $c$, the parameter equation of the edge curve in the Cartesian coordinate system was obtained (Equation (7)).

$$
\left\{\begin{array}{l}
y=\rho_{0}\left[\frac{\sin \varphi_{0}}{\sin \left(\varphi_{0}-K \theta\right)}\right]^{\frac{1}{K}} \sin \theta \\
x=\rho_{0}\left[\frac{\sin \varphi_{0}}{\sin \left(\varphi_{0}-K \theta\right)}\right]^{\frac{1}{K}} \cos \theta
\end{array}\right.
$$

In Equation (7), the value of $x, y$ which are coordinates in the edge curve equation were related to $\rho_{0}$ (the pole radius starting from start point of the edge curve), $\varphi_{0}$ (the static slip angle of the starting point of the cutting edge curve), polar angle $\theta$ and $K$ (static slip angle reduction ratio). In order to effectively make the transition between anti-wrapping blade and blade shaft, the start point of the edge curve A was selected to be on the outside surface of blade shaft, and also on the polar axis $\mathrm{x}$, and in other words, that $\rho_{0}$ was the radius of the blade shaft and value of $\rho_{0}$ was $40 \mathrm{~mm}$. According to other research ${ }^{[34-35]}, \varphi_{0}$ should be $52^{\circ}$ and $K$ should be 0.1 to ensure the optimum cutting performance and reduced power consumption. The end point of the cutting edge curve (E) needs to be a tangent with the side cutting edge of rotary blade to make sure that there was no structural breaks between the parts, thus the point $\mathrm{E}$ was located in the blade seat length and width intersection. According to the national standard GB/T5669-2008, the segment
OF is $95 \mathrm{~mm}$, and segment $\mathrm{FE}$ is $25.5 \mathrm{~mm}$ and angle $\theta_{0}=\arctan$ $(\mathrm{EF} / \mathrm{OF})=15^{\circ}$, so the range of the angle $\theta$ can be: $0 \leq \theta \leq \theta_{\mathrm{m}}=90^{\circ}-\theta_{0}=$ $75^{\circ}$. The above parameter values were substituted into Equation (7) and the cutting edge curve was plotted, as shown in Figure $7 \mathrm{~b}$. In order to simplify subsequent processing, the circumferential direction anti-wrapping blade and axial direction anti-wrapping blade had the same edge curve design. To prevent blade from excessive deformation and attain effective cutting, $65 \mathrm{Mn}$ steel was selected as blade material, the thickness of the blade was set at $5 \mathrm{~mm}$, and edge angle was $30^{\circ}$.

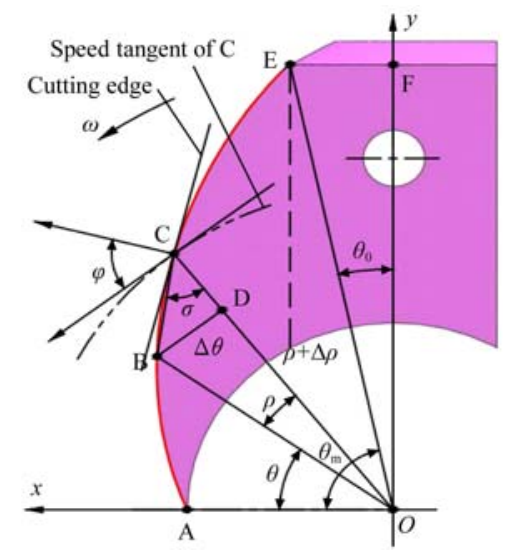

a. Index edge curve analysis diagram

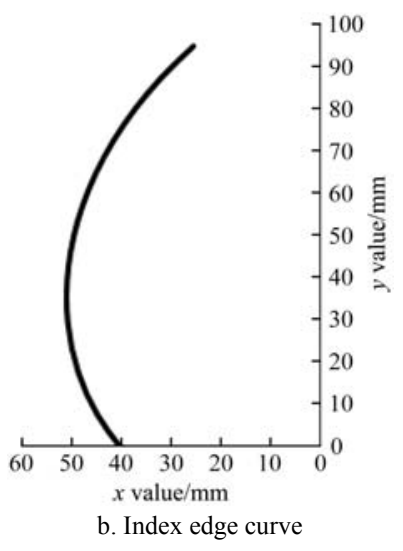

Figure 7 Curve of anti-wrapping blades edge

\subsubsection{Positioning of anti-wrapping cutter blade}

Two anti-wrapping cutting blades were installed in the V-shape subsoiling zone, while one anti-wrapping cutting blade and one counterweight baffle were installed in the non-subsoiled zones. The mass and positioning of the counterweight baffle was equal to the anti-wrapping cutting blade to reduce vibration (Figure 8).

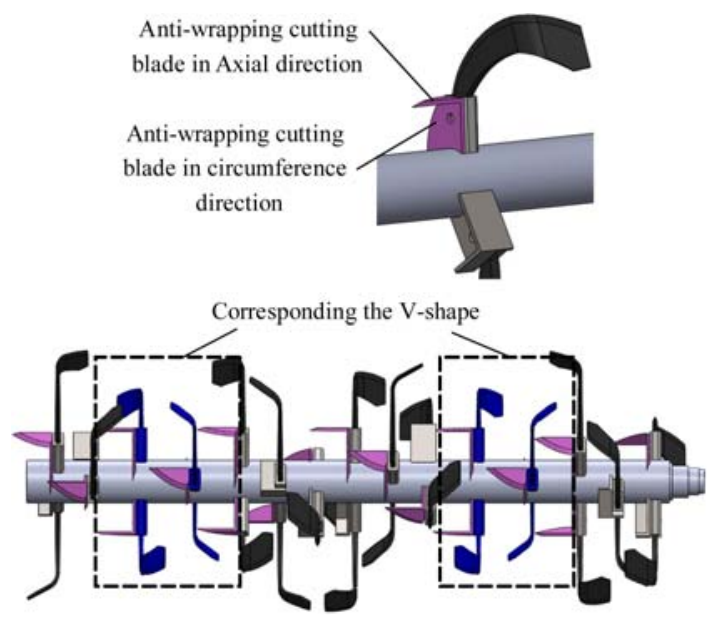

Figure 8 Arrangement of anti-wrapping blades 


\section{Field experiment}

\subsection{Experimental condition}

A field experiment was conducted in June 2017 at a research site in Zhuozhou city, Hebei province $\left(115^{\circ} 56^{\prime} \mathrm{E}, 39^{\circ} 28^{\prime} \mathrm{N}\right)$. An ASRT was compared with a CSRT by assessing field tillage indicators after the operation of each machine.

Typical plot conditions were as follows; average soil bulk density, $1.47 \mathrm{~g} / \mathrm{cm}^{3}$; average soil moisture content, $14.27 \%$; and average soil compactness, $3175.8 \mathrm{kPa}$. Tillage depth was from 0 to $450 \mathrm{~mm}$. Plant residue from the previous maize crop $2.32 \mathrm{~kg} / \mathrm{m}^{2}$ and a considerable number of weeds were chopped and uniformly spread on the field.

Test equipment: Lovol M1104 tractor, ASRT, CSRT(working width $2500 \mathrm{~mm} ; 4$ subsoilers with broken line blade and the distance between the blades is $625 \mathrm{~mm} ; 68$ rotary blades ( 34 on the left and 34 on the right) are arranged in a double-headed spiral, type of rotary blades are IIT245 machete; the same plane inside and outside the staggered rotary blade phase angle is $150^{\circ}$, the same direction of the adjacent rotary blade on the same spiral line is $42^{\circ}$ ), field comprehensive test vehicle (A rotary torque sensor is installed to measure the torque and rotation speed of the rotary parts of SRTs), AIC3600 vibration analyzer (produced by Beijing institute of space intelligence monitoring technology), Revealer 5F01 high-speed camera (produced by Fuhuang Agile Device co., LTD), $2000 \mathrm{~W}$ strong light, compactness measuring instrument, soil box , ring knife, electric thermostat drying oven, tape measure, steel ruler, electronic scales, etc.

\subsection{Methodology}

The operating speed, rotary tillage speed, subsoiling depth and rotary tillage depth were $0.8 \mathrm{~m} / \mathrm{s}, 350 \mathrm{r} / \mathrm{min}, 350 \mathrm{~mm}$ and $150 \mathrm{~mm}$, respectively. The test indexes included vibration reducing, torque and anti-wrapping performance in the process of machine operation, as well as indexes such as tillage depth stability, vegetation cover rate, soil turgor and surface roughness after operation of the two machines. LSD method in SPSS 21 software was used to test the significant difference between the two machines in operation indexes. Specific methods and steps of measurement and calculation were as follows.

4.2.1 Testing for relevant indicators during operation process

1) Vibration acceleration

The flat field with $300 \mathrm{~m}$ in length and $30 \mathrm{~m}$ in width was selected as test plot, and $20 \mathrm{~m}$ in width of it was selected as the measuring area. The single-channel magnetic vibration sensor AIC3600 type vibration analyzer was attached above both sides of the frame of rotary tillage components (Figure 9), and the data were collected when the average operating speed and rotary tillage speed were $0.8 \mathrm{~m} / \mathrm{s}$ and $350 \mathrm{r} / \mathrm{min}$. The vibration acceleration stability value of the machine was recorded every $30 \mathrm{~m}$ with 3 times repetition.

2) Torque

The flat field with $300 \mathrm{~m}$ in length and $30 \mathrm{~m}$ in width was selected as test plot, the first $50 \mathrm{~m}$ and the last $50 \mathrm{~m}$ were set as commissioning area, and the middle $200 \mathrm{~m}$ was test area. Field comprehensive test vehicle was installed between the tractor and the SRT (Figure 10). The torque was collected every $0.1 \mathrm{~s}$ when the average operating speed and rotary tillage speed were $0.8 \mathrm{~m} / \mathrm{s}$ and $350 \mathrm{r} / \mathrm{min}$, and the test duration was $40 \mathrm{~s}$.

3) Anti-wrapping performance

To figure out whether the wrapping of the rotary shaft affected the rotary blade penetrating soil, working operation for $60 \mathrm{~m}$ with 3 repetition was conducted. Revealer 5F01 high-speed camera was used to record the operation process of rotary tillage components at
$750 \mathrm{fps}$, as shown in Figure 11. I-SPEED Suite software was used to reproduce the process of high-speed photographic recording and static images of specific locations were obtained to analyze the influence of anti-wrapping performance.

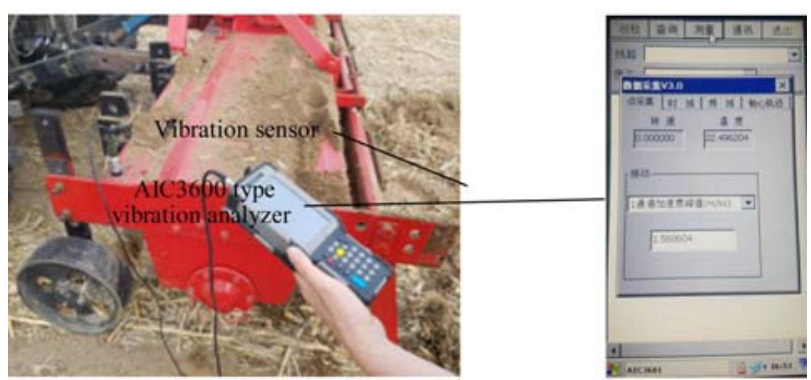

a. Installment of AIC3600 type vibration analyzer b. Interface of data reading Figure 9 Vibration test of SRT

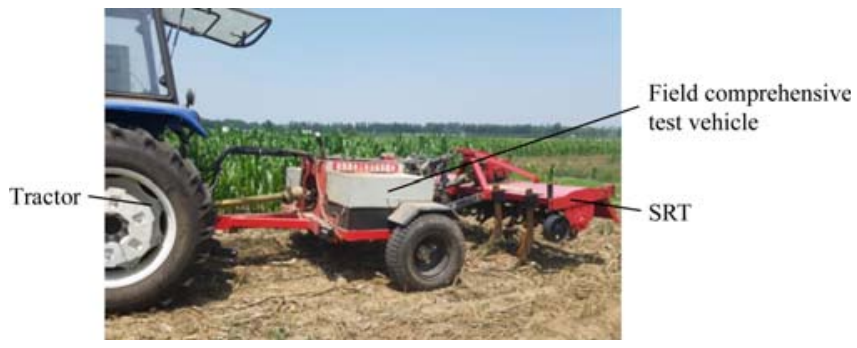

Figure 10 Torque test of SRTs

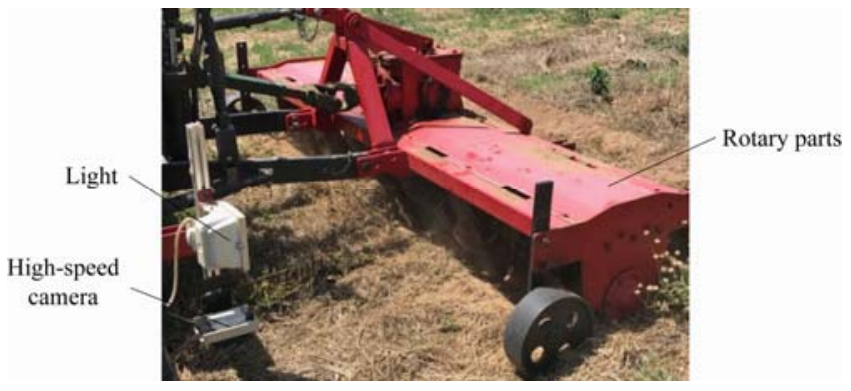

Figure 11 Installation of High Speed Camera

4.2.2 Testing for relevant indicators after operation process

1) Subsoiling depth, rotary tillage depth and their stability

The working stability area was selected for measurement, and the steel ruler was used to measure the vertical distance from the bottom of subsoiling ditch to the field surface. Four points were measured every $5 \mathrm{~m}$, a total of 40 points were measured, and the average value was the subsoiling depth. Along the forward direction, steel ruler was used to measure the rotary tillage depth. Ten points are measured every $5 \mathrm{~m}$, a total of 50 points are measured, and the average value was the rotary tillage depth. The stability coefficients of subsoiling depth and rotary tillage depth were calculated according to Equation (8).

$$
\left\{\begin{array}{l}
a=\frac{\sum_{i=1}^{n} a_{i}}{n} \\
S=\sqrt{\frac{\sum_{i=1}^{n}\left(a_{i}-a\right)^{2}}{n-1}} \\
V=\frac{S}{a} \times 100 \% \\
U=1-V
\end{array}\right.
$$

where, $a$ is the average depth of subsoiling or rotary $(\mathrm{cm}) ; a_{i}$ is the depth of subsoiling or rotary at the $i$ th point $(\mathrm{cm}) ; n$ was the number of measured points; $S$ is the depth standard deviation of subsoiling or rotary $(\mathrm{cm}) ; V$ is the depth variation coefficient of 
subsoiling or rotary; $U$ is the depth stability coefficient of subsoiling or rotary.

2) Vegetation cover rate

The five-point sampling method was adopted in the working operation stability area to measure the weight of $1 \mathrm{~m}^{2}(1 \mathrm{~m} \times 1 \mathrm{~m})$ vegetation (straw, weed and root stubble) on the surface before the operation of the two SRTs, and the average value was $W_{\mathrm{q}}$; The same method was used to measure the weight of vegetation after the operation of the two SRTs, and the average value was $W_{\mathrm{h}}$. Equation (9) was used to calculate the vegetation cover rate $Y$ of the two SRTs.

$$
Y=\frac{W_{\mathrm{q}}-W_{\mathrm{h}}}{W_{\mathrm{q}}} \times 100 \%
$$

3) Soil bulking intensity

The operation stability zones of the two kinds of SRT were selected to draw the uncultivated surface lines, cultivated surface lines and subsoiling bottom lines at the same location, respectively. In addition, the above drawing lines in the same planes were all perpendicular to the STRs' forward direction. Defining the cross-sectional area before and after operation of the SRTs was $A_{\mathrm{q}}$ and $A_{\mathrm{h}}$, respectively (Figure 12). Soil bulking intensity $P$ can be obtained by Equation (10)

$$
P=\frac{A_{\mathrm{h}}-A_{\mathrm{q}}}{A_{\mathrm{q}}} \times 100 \%
$$

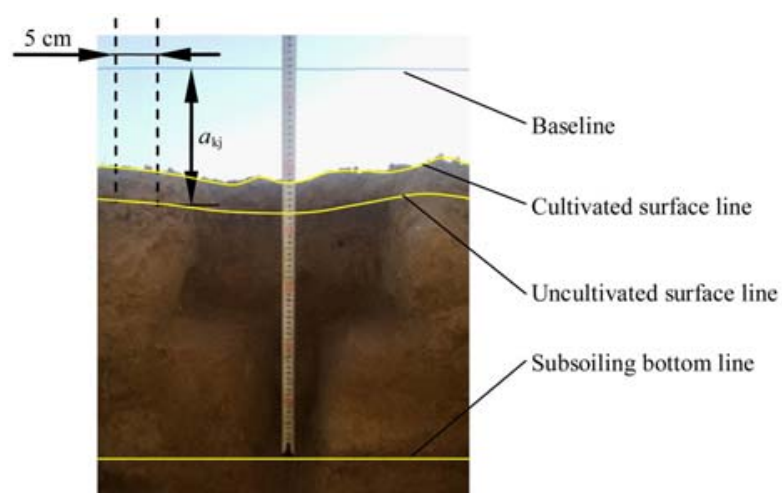

Figure 12 Measurement of Soil Bulking intensity and Surface Flatness

4) Surface flatness

A horizontal baseline was set crossing the highest surface lines before and after operation of the SRTs (Figure 12). Equal interval points were marked in $50 \mathrm{~mm}$ interval of the whole machine's operation width $(2500 \mathrm{~mm})$. Before and after operation of the two SRTs, vertical distances between these equal interval points and baseline at same positon were measured. The mean and standard deviation can be calculated by Equation (11), in which standard deviation represented as surface flatness. Furthermore, experiments repeated 5 times.

$$
\left\{\begin{array}{l}
a_{k}=\frac{\sum_{j=1}^{n_{k}} a_{k j}}{n_{k}} \\
S_{k}=\sqrt{\frac{\sum_{j=1}^{n_{k}}\left(a_{k j}-a_{k}\right)^{2}}{n_{k}-1}}
\end{array}\right.
$$

where, $k$ is the measurement times, $k=5 ; a_{\mathrm{k}}$ is the mean vertical distance at $k^{\text {th }}$ measurement; $a_{k j}$ is the vertical distance at $k^{\text {th }}$ measurement of the $j^{\text {th }}$ equal interval point; $n_{k}$ is the measured points' number at $k^{\text {th }}$ measurement; $S_{k}$ is the surface flatness at $k^{\text {th }}$ measurement.

\subsection{Results}

\subsubsection{Test indexes}

The results of vibration acceleration, torque and anti-wrapping effect of the two SRTs are tabulated in Table 1. The average vibration acceleration of the ASRT $\left(2.13 \mathrm{~m} / \mathrm{s}^{2}\right)$ was significantly reduced by $59.05 \%$, compared with the CRST $\left(52.09 \mathrm{~mm} / \mathrm{s}^{2}\right)$. The average torque $(784.78 \mathrm{~N} \cdot \mathrm{m})$ reduction was not significant in the ASRT when compared with CSRT $(839.30 \mathrm{~N} \cdot \mathrm{m})$. Observed wrapping of plant residue was not evident in all 3 journeys with ARST, while the CSRT experienced wrapping in all 3 journeys. High speed camera was applied to observe the rotary parts' wrapping process (Figure 13). Results showed that the roller equipped with anti-wrapping blades can effectively make weeds and straw slide off blade seats, and reduce wrapping of the roller.

Table 1 Results of test indexes

\begin{tabular}{lcc}
\hline \multicolumn{1}{c}{ Testing index } & ARST & CRST \\
\hline Vibration acceleration $/ \mathrm{m} \cdot \mathrm{s}^{-2}$ & $2.13 \pm 8.1 \mathrm{a}$ & $5.2 \pm 16.9 \mathrm{~b}$ \\
Torque $/ \mathrm{N} \cdot \mathrm{m}$ & $785 \pm 68 \mathrm{a}$ & $839 \pm 99 \mathrm{a}$
\end{tabular}

Anti- wrapping effect Un-wrapped for journey Wrapped for journey 1, 2 Anti- wrapping effect 1,2 and 3 and 3

Note: Values followed by different lower case letters indicated that the difference between ASRT and CRST were significant $(P<0.05)$; same below.
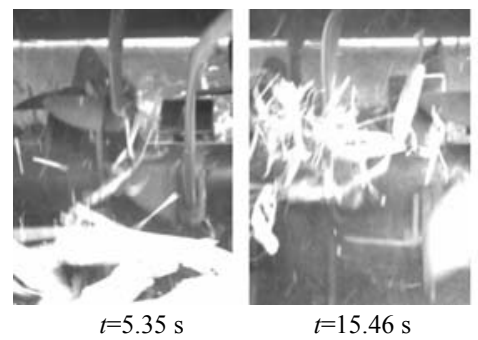

$t=15.46 \mathrm{~s}$

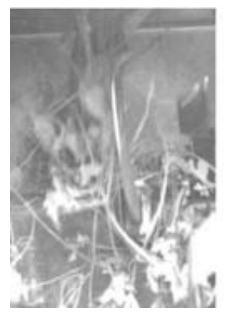

$t=4.735 \mathrm{~s}$

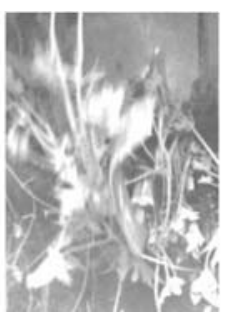

$t=13.77 \mathrm{~s}$
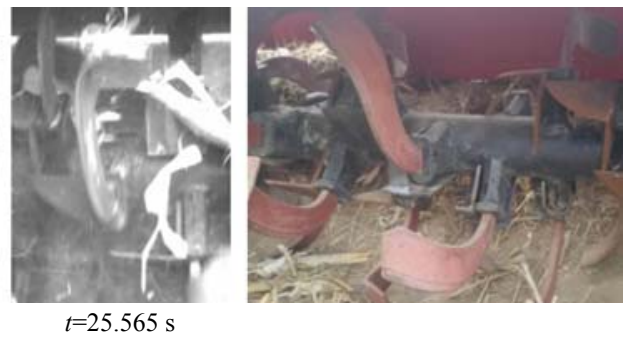

(a) ASRT
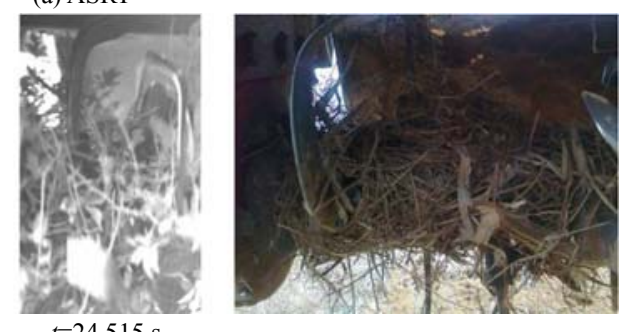

$t=24.515$

(b) CRST

Figure 13 Wrapping process of rotary parts 


\subsubsection{Tillage and soil effect following SRT operations}

The field test results indicated that, rotary tillage depth and stability, subsoil depth, subsoil depth and stability, straw coverage rate, soil bulking intensity, soil surface flatness were acceptable according to the industrial standards laid out in $J B / T 10295-2014^{[36]}$ for SRT (Table 2). Compared with CSRT, the stability of rotary tillage depth of the ASRT was significantly improved by $5.01 \%$. While for other indices, there were no significances.

Table 2 Field test results after machine operation

\begin{tabular}{lccc}
\hline \multicolumn{1}{c}{ Performance index } & ARST & CRST & National standard \\
\hline Rotary tillage depth/cm & $15.1 \pm 1.14 \mathrm{a}$ & $13.3 \pm 1.86 \mathrm{a}$ & $\geq 8$ \\
Rotary tillage depth stability/\% & $91.2 \pm 1.61 \mathrm{a}$ & $86.6 \pm 2.37 \mathrm{~b}$ & $\geq 85$ \\
Subsoil depth/cm & $34.8 \pm 1.51 \mathrm{a}$ & $33.7 \pm 2.23 \mathrm{a}$ & $\geq 25$ \\
Subsoil depth stability/\% & $94.1 \pm 2.03 \mathrm{a}$ & $92.2 \pm 3.18 \mathrm{a}$ & $\geq 80$ \\
Straw coverage/\% & $83.3 \pm 2.94 \mathrm{a}$ & $84.5 \pm 2.72 \mathrm{a}$ & $\geq 60$ \\
Soil tilth/\% & $16.3 \pm 0.78 \mathrm{a}$ & $14.8 \pm 0.90 \mathrm{a}$ & $10 \sim 40$ \\
Soil surface flatness/cm & $1.8 \pm 0.36 \mathrm{a}$ & $2.0 \pm 0.47 \mathrm{a}$ & $\leq 4$ \\
\hline
\end{tabular}

\subsection{Discussion}

\subsubsection{Reasons for vibration reduction}

According to the test, the average vibration acceleration of the ASRT was significantly reduced by $59.05 \%$, compared with the CSRT. The main reasons were: two arrangement types were applied on long/short rotary blades of the vibration reduction and anti-wrapping components. The long rotary blades entered into the uncultivated soil area in turn and subjected to large force, which were designed for heavy residue and hard soils. The short rotary blades entered into the V-shape subsoiling areas in turn and subjected to relative small force, which were mainly used for burying the furrows formed by subsoiler. Rotary blades of the CSRT were mounted on a single helix and rotated into soil in succession. Rotary blades' force will be changed suddenly when they rotated from uncultivated area to subsoiling area, which would made the vibration of machine. The vibration reduction and anti-wrapping components reduced the impact and vibration on blade shaft from rotary blades, which was beneficial to prolong the service life of rotary blades, bearings and gearboxes. Moreover, the results showed that the wear of the rotary blades were uniformly, which was helpful to improve working efficiency and reduce the frequency of changing rotary blades.

\subsubsection{Reasons for torque reduction}

The average torque reduction was not significant in the ASRT when compared with CRST. The main reasons were as follows: (1) Vibration reduction and anti-wrapping components were designed according to the soil surface after subsoiling and with 60 rotary blades in total, while for CSRT there were 68 rotary blades. When compared with ASRT, vibration reduction and anti-wrapping components decreased the number of powered rotary blades, thus reduced the average torque. (2) V-shape subsoiling area was formed by subsoilers of two SRTs and soil was soft, which resulted in little different forces of two SRTs' rotary blades. In addition, the soil compactness of surface was unevenly, which lead to the nonsignificant torque difference of rotary components.

\subsubsection{Reasons for effective anti-wrapping}

The CSRT experienced wrapping in all 3 journeys, while straw wrapping was not observed for the ASRT. By experiment, we found that rotary parts of the CSRT in uncultivated area were wrapped seriously. Reasons may be that: soil, weeds and straw in V-shape subsoiling area were all upraised and moved to both sides of subsoiler, which led to blade seats and blade shafts wrapped with weeds and straw easily. Wrapping processes of rotary parts were divided as follows: (1) Blade seats hanging weeds. Weeds and straw were easily hanged at the joint area of blade seats and blade shaft, and the amount of hanging weeds and straw increased with the rotation of blade shaft. (2) Blade shaft winding straw, weeds. Corresponding with the increase amount of weeds hanged on blade seats, long straw and weeds in front of rotary parts were attached at blade seats and finally wrapped on the blade shaft. (3) Formation of an isolation layer. With the progress of the operation, more and more straw and weeds were wrapped around the blade shaft, gradually forming straw and weed isolation layer. Anti-wrapping blades were assembled in axial and circumferential directions of the vibration reduction and anti-wrapping components, which reduced blade seats hanging weeds and blade shaft winding straw and weeds. Thus, the rotary parts obtained the function of anti-wrapping.

4.4.4 Reasons for stability of rotary tillage depth enhancement

The average rotary tillage depth of vibration reduction and anti-wrapping components was $15.07 \mathrm{~cm}$, which met the working requirement. While for the CSRT, the average rotary tillage depth was $13.27 \mathrm{~cm}$, which couldn't meet the working requirement. The reason was that isolation layer formed by wrapping straw and weeds on the blade shaft upraised the whole blade roller, which led rotary blades unable to achieve the expected tillage depth. In addition, instability of the rotary tillage depth caused by wrapping weeds and vibration in the rotary parts of CSRT reduced the stability of rotary tillage depth. Above all, vibration reduction and anti-wrapping components not only guarantee subsoil depth and stability, straw coverage rate, soil bulking intensity and soil surface flatness, but also enhanced stability of rotary tillage depth, decreased vibration, torque and weeds/straw wrapping.

\section{Conclusions}

Redesign of SRT rotary components reduced vibration and prevented residue wrapping, thus improved its suitability for fields with plant residue retention in Northern China. Based on discrete element simulation and field experiments the adaption of long and short rotary blades on different helixes according to soil disruption after subsoiling, was effective in reducing vibration and improving soil surface outcomes, IT225 type rotary blades with two anti-wrapping blades and a working width of $60 \mathrm{~mm}$ were recommended for the subsoiled zone, and IIT245 type rotary blades with one anti-wrapping blade and a working width of $50 \mathrm{~mm}$ were recommended for the zones between the subsoiling tines. Comparative field tests showed that the ASRT reduced vibration acceleration by $59.05 \%$ and increased rotary tillage depth stability by $5.01 \%$. Anti-wrapping blades mounted on the rotary roller in axial and radial directions effectively reduced residue and weed wrapping of rotary parts. The recommended anti-wrapping blade, should be made from $65 \mathrm{Mn}$ steel, $5 \mathrm{~mm}$ thick, have an exponential curve and blade angle of $30^{\circ}$. Overall these modifications improved SRT working efficiency and operation time, thereby reducing wear and increases the longevity of the machine.

\section{Acknowledgements}

The authors gratefully acknowledge that this research was financially supported by the Modern Agricultural Industry Technology System (Grant No. CARS-03), Special Fund for Agro-scientific Research in the Public Interest from the Ministry of Agriculture, China (Grant No. 201503136), Innovative Research Team in University of China (Grant No. IRT13039). 


\section{[References]}

[1] Zhang X R, Wang C, Chen Z H, Zeng Z W. Design and experiment of a bionic vibratory subsoiler for banana fields in southern China. Int J Agric \& Biol Eng, 2016; 9(6): 75-83.

[2] Zhao W, Zhang W C, Zhou Z L, Niu Y, Zhao D Z. Development and experimental research of combined subsoiling and rotary tilling set. Transactions of the CSAE, 2007; 23(1): 125-128. (in Chinese)

[3] Sun D X, Zhang A M, Gong J X. Design and experiment on 1SZL-250A type subsoiling rotary tillage fertilizer combined soil working machine. Journal of Chinese Agricultural Mechanization, 2016; 37(4): 1-6. (in Chinese)

[4] Zhang R F, Yang H S, Gao J L, Zhang Y Q, Wang Z G, Fan X Y, et al. Effect of subsoiling on root morphological and physiological characteristics of spring maize. Transactions of the CSAE, 2015; 31(5): 78-84. (in Chinese)

[5] Zheng C Y, Yu Z W, Shi Y, Cui S M, Wang D, Zhang Y L, et al. Effect of tillage practices on water consumption, water use efficiency and grain yield in wheat field. Journal of Integrative Agriculture, 2014; 13(11): 2378-2388.

[6] Ma S Y, Yu Z W, Shi Y, Gao Z Q, Luo L P, Chu P F, et al. Soil water use, grain yield and water use efficiency of winter wheat in a long-term study of tillage practices and supplemental irrigation on the north china plain. Agricultural Water Management, 2015; 150: 9-17.

[7] Sojka R E, Horne D J, Ross C W, Baker C J. Subsoiling and surface tillage effects on soil physical properties and forage oat stand and yield. Soil and Tillage Research, 1997; 40(3-4): 125-144.

[8] Zheng K, He J, Wang Q J, Li W Y, Zhang Z Q. The current research status of combined tillage machine. Journal of Agricultural Mechanization Research, 2016; 38(1): 257-263. (in Chinese)

[9] Zhao W, Zhou Z L, Niu Y, Ma Y, Zhao D Z. Development of subsoiling and rotary tilling unit. Transaction of the CSAM, 2007; 38(2): 79-82. (in Chinese)

[10] $\mathrm{Hu} \mathrm{H} \mathrm{N,} \mathrm{Lu} \mathrm{C} \mathrm{Y,} \mathrm{Wang} \mathrm{Q} \mathrm{J,} \mathrm{Li} \mathrm{H} \mathrm{W,} \mathrm{He} \mathrm{J,} \mathrm{Xu} \mathrm{D} \mathrm{J,} \mathrm{et} \mathrm{al.} \mathrm{Influences} \mathrm{of}$ wide-narrow seeding on soil properties and winter wheat yields under conservation tillage in north china plain. Int J Agric \& Biol Eng, 2018; 11(4): 74-80.

[11] Zhang Z J, Jia H L, Sun J Y. Review of application of biomimetics for designing soil-engaging tillage implements in northeast China. Int $\mathrm{J}$ Agric \& Biol Eng, 2016; 9(4): 12-21.

[12] He J, Li H W, Wang Y K, Zhang Z Q, Wang Q J. Thoughts on developing small/medium size no-till equipment for conservation agriculture in Asia: Summary of post-publication peer review comments. Int J Agric \& Biol Eng, 2014; 7(5): 139-146.

[13] Li S T, Chen X B, Chen W, Zhu S P, Li Y W, Yang L, et al. Soil-cutting simulation and parameter optimization of handheld tiller's rotary blade by Smoothed Particle Hydrodynamics modeling and Taguchi method. Journal of Cleaner Production, 2018; 179: 55-62.

[14] Matin M A, Desbiolles J M A, Fielke J M. Strip-tillage using rotating straight blades: effect of cutting edge geometry on furrow parameters. Soil and Tillage Research, 2016; 155: 271-279.

[15] Matin M A, Fielke J M, Desbiolles J M A. Furrow parameters in rotary strip-tillage: effect of blade geometry and rotary speed. Biosystems Engineering, 2014; 118: 7-15.

[16] Matin M A, Fielke J M, Desbiolles J M A. Torque and energy characteristics for strip-tillage cultivation when cutting furrows using three designs of rotary blade. Biosystems Engineering, 2015; 129: 329-340.

[17] Saimbhi V S, Wadhwa D S, Grewal P S. Development of a rotary tiller blade using three-dimensional computer graphics. Biosystems
Engineering, 2004; 89(1): 47-58.

[18] Yang Y S, Fielke J, Ding Q S, He R Y. Field experimental study on optimal design of the rotary strip-till tools applied in rice-wheat rotation cropping system. Int J Agric \& Biol Eng, 2018; 11(2): 88-94.

[19] Lee K S, Park S H, Park W Y, Lee C S. Strip tillage characteristics of rotary tiller blades for use in a dryland direct rice seeder. Soil \& Tillage Research, 2003; 71(1): 25-32.

[20] Chaturvedi V, Kumar A, Singh J K. Strip tillage characteristics of rotary tiller blades for use in a dryland direct rice seeder. Applied Ergonomics, 2012; 43: 891-901.

[21] Xu L, Xiao H R. Analysis of the winding grass mechanism for tea cultivation machinery. Journal of Chinese Agricultural Mechanization, 2015; 36(2): 25-28. (in Chinese)

[22] Zheng K, He J, Li H W, et al. Research on polyline soil breaking blade subsoiler based on subsoiling soil model using discrete element method. Transaction of the CSAM, 2016; 47(9): 62-72. (in Chinese)

[23] Zheng H G, Zhang Z Q, Xu W B, Wei Y, Guan Y Z, Xu K Y. Based on soil compression and failure theory of digging shovel design and analysis. Journal of Agricultural Mechanization Research, 2011; 33(11): 122-126. (in Chinese)

[24] Chinese Standard Committee. Subsoiler and share shaft, JB/T 9788-1999. Chinese Standard Press, China, 1999. (in Chinese)

[25] Wang X Z, Gao P Y, Yue B, et al. Optimisation of installation parameters of subsoiler' wing using the discrete element method. Computers and Electronics in Agriculture, 2019; 162: 523-530.

[26] Chinese Standard Committee. Rotary tiller - rotary blades and blade holders, GB/T 5669-2008. Chinese Standard Press, China, 2008. (in Chinese)

[27] Fang H M, Zhang Q Y, Chandio F A, Guo J, Sattar A, Arslan C, et al. Effect of straw length and rotavator kinematic parameter on soil and straw movement by a rotary blade. Engineering in Agriculture, Environment and Food, 2016; 9(3): 235-241.

[28] Chinese Academy of Agricultural Mechanization Sciences. Agricultural machinery design manual. Beijing: China's Agricultural Science and Technology Press, 2007. (in Chinese)

[29] Zhang Q, Liang L S. Agricultural machines. Beijing: Chemical Industry Press, 2016. (in Chinese)

[30] Ding Q S, Ge S Y, Ren J, Li Y. Characteristics of subsoiler traction and soil disturbance in paddy soil. Transaction of the CSAM, 2017; 48(7): 47-56. (in Chinese)

[31] Lin J, Wang L, Li B F, Tian Y, Bo H M, Ma T. Design and test of 2ZZ-3 type deep scarification-terrace ridge-fertilization combine intertill machine. Transactions of the CSAE, 2016; 32(24): 9-17. (in Chinese)

[32] Jia H L, Huang D Y, Liu X L, Wang Z H, Liu Z C, Ma C L. Symmetrical multi-spiral arrangement of tillage blades on rotor. Transactions of the CSAE, 2011; 27(4): 111-116. (in Chinese)

[33] Feng P Z. Optimum number sequence arrangement of rotary tiller blades. Journal of Jiangsu Institute of Technology, 1985; 6(4): 40-49. (in Chinese)

[34] Wang J W, Wang Q, Tang H, Zhou W Q, Duo T Y, Zhao Y. Design and experiment of rice straw deep buried and whole straw returning device. Transactions of the CSAM, 2015; 46(9): 112-117. (in Chinese)

[35] Kang J M, Li S J, Yang X J, Liu L J. Structure parameters optimization of sine exponential curve type ditching blade. Transactions of the CSAM, 2016; 47(11): 91-99. (in Chinese)

[36] Chinese Standard Committee. Combined implement for subsoiler and cultivating, JB/T10295-2014. Chinese Standard Press, China, 2014. (in Chinese) 